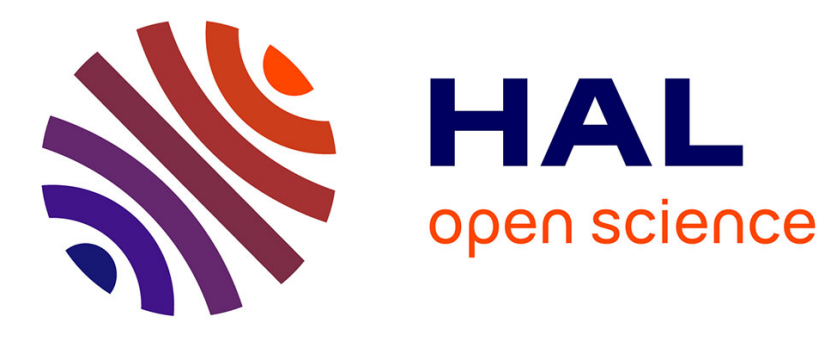

\title{
Toy commercials across Europe
}

Simona de Iulio, Zouha Dahmen-Jarrin

\section{- To cite this version:}

Simona de Iulio, Zouha Dahmen-Jarrin. Toy commercials across Europe. Young Consumers, 2004, 5 (4), pp.39-45. 10.1108/17473610410814319 . halshs-02013485

\section{HAL Id: halshs-02013485 \\ https://shs.hal.science/halshs-02013485}

Submitted on 11 Feb 2019

HAL is a multi-disciplinary open access archive for the deposit and dissemination of scientific research documents, whether they are published or not. The documents may come from teaching and research institutions in France or abroad, or from public or private research centers.
L'archive ouverte pluridisciplinaire HAL, est destinée au dépôt et à la diffusion de documents scientifiques de niveau recherche, publiés ou non, émanant des établissements d'enseignement et de recherche français ou étrangers, des laboratoires publics ou privés. 


\section{Toy commercials across Europe}

In this study Simona De Iulio, University of Strasbourg and Zouha Jarrin, University of Grenoble, reveal some interesting findings about globalisation, advertising and child culture by comparing toy commercials from France, Germany and Italy.

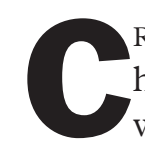

Ritical anAlyses of globalisation have often denounced the spread of a world-wide child culture founded on a standardised array of practices and values promoted by large multinational companies. In this interpretation, young people everywhere have been transformed into 'world-consumers' induced to demand the same goods, play with the same toys, and feed their imaginations with the same themes and symbols. To quote No Logo by the Canadian journalist Naomi Klein: 'The branded multinationals may talk diversity, but the visible result of their actions is an army of teen clones marching - in "uniform", as the marketers say - into the global mall. Despite the embrace of poly-ethnic imagery, market-driven globalisation doesn't want diversity; quite the opposite. Its enemies are national habits, local brands and distinctive regional tastes.' (Klein 2000) It could be said that advertisements for international brands and products targeted at children and adolescents are the most eloquent expression of commercial universalism. In the age of globalisation, it is alleged, not only does advertising flatten children's culture into the worship of commodities and extravagance but it is one of the principal causes of the erosion of national and local traditions.

\section{Advertising strategies}

The arguments put forward by certain marketing experts help consolidate the image of advertising as a steamroller that crushes customs and traditions rooted in national child cultures. Businesses are recommended to divide the younger public according to age and sex (Roedder John 1999): that is, according to demographic data, not according to socio-cultural criteria as well. As Inès de la Ville observes (2004), studies on young consumers concur in representing children as dominated by innate and immutable instincts, rather than focusing on the fact that they grow in a specific social and cultural context.

If businesses do not take account of either the variety of factors that regulate consumption practices or the socio-cultural specificities of countries, they focus on universal attributes of children: they appeal to common denominators in order to act on 'primary' needs and desires. From this point of view, standardising advertising strategies and messages are the best way to address younger international target groups. James U. McNeal, for example, advises: 'In general, it appears that before there is a geographic

Studies on young consumers concur in representing children as dominated by innate and immutable instincts, rather than focusing on the fact they grow in a specific social and cultural context 
culture there is a children's culture; that children are very much alike around the industrialised world. They love to play, first and foremost, they love to snack, mainly on sweets, and they love being children with other children (in contrast to assuming most adult roles). The result is that they very much want the same things, that generally translate their needs into similar wants that tend to transcend culture. Therefore, it appears that fairly standardised multinational marketing strategies to children around the globe are viable.' (McNeal 1992)

However, careful analysis of international marketing strategies reveals that advertising is unable to stand as the new Esperanto. Indeed, although the advertising industry appears to be dominated by the principles of globalisation - expansion, financial concentration, economies of scale, and standardisation - the endeavour to accomplish a single and universal message has failed. Since the 1980s, international marketing practices have shifted towards strategies which exclude the extreme options of total standardisation and total diversification. The main aim today is to strike a balance between the coherence of the international image of a product or brand and its declension according to specific national settings (de Mooij, 1998).

Although it promotes standardised products, international advertising aimed at children and adolescents appears to result from a trade-off between economic pressures towards standardisation and the specific socio-cultural features of each national market, which instead impose adaptation and diversification.

\section{The aims and methods of the research}

The aim of our research was to highlight the relationship between advertising and children within the context of globalisation. We investigated the roles performed by different territories - international, national, regional and local - in

\section{The fusion of film, animated sequences and digital images, as well as the use of visual devices and sound effects, helped transform the toy into a key which provided entry into a dream-world.}

advertising directed at children of different nationalities and examined the role of advertising aimed at children in the globalisation of child culture. Attention focused in particular on the apparent tendency towards universalism in the form and content of television commercials targeted at children, and the changes made to the commercials so that their messages appeal to young French, Italian and German television viewers.

The discussion in this article is based on comparative analysis of a sample of 163 television commercials broadcast during the week from 17 -23 November 2003 on TF1 (France), Italia Uno (Italy), Super RTL A (Germany) during programmes explicitly intended for children and aired between the hours of seven to eight-thirty $\mathrm{am}$. The sample examined consisted solely of toy commercials. The choice of toy commercials was dictated by contingent reasons (in November the majority of commercials broadcast during children's programmes are for toys) and theoretical ones given that toys are 'the key instruments of child culture' (Kline 1993).

The comparative method, and the descriptive and socio-semiotic approach used, enabled us to study the strategies, forms and contents of advertising discourses directed at children, without neglecting the context in which those discourses were transmitted. The commercials were examined on the basis of a grid designed to determine the extent to which advertising aimed 
at children uses standardised solutions and the extent to which it instead adapts to national or local children's cultures.

We isolated in the sample 19 commercials which promoted the same toys in two or all three countries. Given that these commercials were particularly significant for our purposes, they were subjected to more detailed analysis: after being transcribed in their entirety, they were compared using the interpretative grid.

\section{Homogeneity of strategies and contents}

Analysis of the sample revealed a set of constant features in the strategies employed in advertising toys to young French, Italian and German television viewers. The commercials examined made simultaneous use of various modes of persuasion. On the one hand, they adopted the register of informative-rational argument by describing the product's features and performance. On the other, they exploited the register of seduction and emotion by appealing to the imagination. This overlapping of different persuasive registers was accompanied by a mix of different advertising genres. The descriptive presentation (a voice-over describing the properties of the toy - often the sole protagonist of the video track - and how it worked) was associated with spectacular animations, a fantastical atmosphere, and the surprise of special effects.

The boundary between reality and fiction was therefore very fine. Images of different kinds (film, animation or synthesis) alternated or merged in the same shot, so that flesh-and-blood children, toys and cartoon characters all appeared on the screen, moving in a domain where the real and imaginary worlds intermingled. In the French and German commercials for My Scene Barbie, for example, animated characters, dolls and small girls interacted in a setting where 'real' snow in the foreground combined with painted fir trees, mountains and hills in the background. Likewise, Hot Wheels model cars seemed at times to be racing on the toy Turbo fet City track and then in the virtual space of a video game. In other cases, the realism of the representation was altered by the use of special effects to emphasise certain of the toy's properties.

The fusion of film, animated sequences and digital images, as well as the use of visual devices and sound effects, helped transform the toy into a key which provided entry into a dream-world. Toy advertising aims to reproduce the mechanisms of children's typical play. The commercials depicted toys as instruments able to activate the imagination, the toys could give access to extraordinary (imaginary) experiences. The setting in which the game was played (often a child's bedroom) was anonymous, and the child's presence was marginal. The child playing with the toy was often relegated to second place, shrunk by a wide-angle shot which instead magnified the size of the toy. Some commercials showed only the hands and fingers of a child manipulating the product; and in some cases the child-player disappeared altogether, with the toy seemingly moving on its own.

The toys often came to life in the commercials as the protagonists of stories. As Stephen Kline notes, advertising strategies increasingly rely on characterisation and personification (Kline 1993). In other words, it is not simply plastic dolls or teddy bears that appear on the screen, but individuals with names, personalities and social roles. Advertising attributes meaning to toys by associating them with a set of rules and rituals, every toy is related to a desired array of experiences and emotions. The commercial enacts a manner of playing and having fun, thus seeking to seduce children into believing that the toy will give them access to a special world and to a specific experience.

The world associated with the toy is inspired by stereotypical situations which the advertisers believe figure in the dreams of boys (visiting farm animals in the Alle meine Schweinchen/ I Maialini Ballerini commercial) or of girls (taking care of a 
baby in Barbie Mix \& Magic Küchel Barbie Cucina Magiche Delizie) or of pre-adolescents (an evening at the discotheque with the My Scene dolls; a stroll through the shopping centre with $L e$ centre commercial Polly Pocket/Il centro commerciale di Polly). In these examples, shots of the product alternate with images representing emblematic places: the farmyard, the dance floor of a discotheque, the escalator in a shopping centre.

In other cases, the toy refers to a fantasy world depicted in films, animated cartoons and television series for children. This occurs when the toy is derived from another media such as a television programme or book and advertising of the toy is part of a broader commercial strategy. In the commercials analysed, characters such as Batman, Transformers and Power Rangers, or objects like the Palais des Princesses, and The Tree of Winnie the Pooh, were taken from the fictitious world of animated films, books or strip cartoons and became real toys in the hands of a child. A connection between the toy and other media sometimes appeared in the final frame, which promoted films, videos and DVDs (for example Bionicle, The Incredible Hulk, Barbie Lac des Cygnes).

The comparative analysis revealed recurrent features not only in strategy, but also in content. The latter was distinguished by gender. For girls, in all three countries, the recurrent themes concerned the world of fashion (trying on clothes, shoes and jewellery, purchasing and exchanging them, applying make-up, styling hair), fairy tales (spells, magic objects, enchanted castles), the pleasure of shopping (some commercials, like those for Il Registratore di Cassa di

\section{For girls, in all three countries, the recurrent themes concerned the world of fashion, fairy tales, the pleasure of shopping, tenderness and motherhood}

Barbie or le centro commerciale di Polly, were outright initiations into consumption), tenderness (attachment to cuddly animals like Winnie the Pooh, Hamtaro) and motherhood. In all three countries, the themes for boys were speed (car races with spectacular accidents), adventure (journeys in exotic lands) and strength (battle and combat). Also to be noted is that the male/ female distinction also concerned the way in which children play: girls were shown playing together; boys were always represented as competing adversaries.

In all countries, moreover, toy advertising is often accompanied by references to a widely shared extra-textual body of knowledge. The commercials utilised motifs taken from European and North American literature (fairy tales and adventure stories), from the cinema (action and adventure films), and from Japanese animated cartoons (Manga). They sometimes drew on the culture of consumption by referring to commercial practices aimed at adults, like telesales or domestic sales (for example Barbie Cucina Magiche Deliziel Barbie Mix E Magic Küche) or car commercials like Lil'Bratz Mini Coupé. Toy commercials therefore tend to refer to a body of knowledge connected with a mass culture shared by children of different nationalities.

\section{From standardisation to adaptation}

The international commercials analysed were much more standardised than those for other categories of products. While the international advertising of food products for children largely relies on 'multi-domestic' solutions or specific national campaigns (De Iulio 2004), all the international toys in our sample took a 'global' approach, transfering the same commercial from one country to another. This transfer always required changes to be made to the video and sound tracks. The comparative analysis showed that the visual and auditory elements making up a commercial may be subjected to six types of operation: repetition, addition, removal, 
shift, translation, replacement. Analysis of the 19 commercials, in fact, revealed that the standardised approach at the strategic level was combined with tactics diversified for each of the three countries.

Comparison of the names given to brands and products yielded insight into the logic behind commercials aimed at children of different nationalities. In the majority of cases, brand names were identical in all three countries (for example, the brand names LEGO, Mattel and Hasbro remained the same, the only exception being GIG/Ban Dai). By contrast, the names of products often underwent literal translation (for example Barbie Registratore di Cassal Registrierkasse, Barbie Lac des Cygnes/ Barbie Lago dei Cignil Barbie Schwanensee), adaptation (Maialini Ballerinil Alle meine Schweinchen, names alluding to the titles of two children's songs well-known in Italy - 'Il Pulcino Ballerino' - and in Germany - 'Alle meine Entchen'), or substitution (Boby Bau \& Friends/ FurReal E Friends). This name differentiation relates to a broader strategy of 'territorial mimicry' intended to tie the brand, and in particular the product, to the national context.

\section{Video changes}

In general, images can traverse national boundaries which are instead barriers to language. Consequently, the adaptation of video tracks in the commercials gave rise to minimal, sometimes imperceptible, discordances. The product packaging might be replaced, and details of the setting altered. The removal or addition of frames in the sequence changed - sometimes superficially, sometimes substantially - the presentation of the toy and the general meaning of the commercial. This was the case, for example, of the cuddly dogs FurReal E Friends/ Boby Bau $\mathcal{E}$ Friends, where the original iconic material was changed to construct two different micronarratives. In the German version, the FurReal toy dog was entered for a dog show by a little girl, and thanks to its beauty and obedience, won

\section{The toy was the same (a cuddly dog) but the meanings attached to it changed (competitiveness/ excellence in the German version, friendship/ tenderness in the Italian one).}

first prize. In the Italian version, the dog show sequence was removed or cut: the video track showed the same little girl strolling in the park with her Boby Bau, which walked and barked like a real dog. The toy was the same (a cuddly dog) but the meanings attached to it changed (competitiveness/excellence in the German version, friendship/tenderness in the Italian version). Also the form of play was different (a dog competition in the German version/ a walk in the park in the Italian one).

Another example of video track adaptation was provided by toy commercials involving several characters or objects (though these are sold separately) stage-managed to create a microstory. The comparative analysis showed that certain sequences were removed, replaced and/or added according to the country, the purpose being to highlight one or another component. For example, the German commercial for Barbie Happy Family was centred on the family car, while the Italian one focused on the Barbie Pediatra doll.

Finally, comparison among video tracks showed that the marketing initiatives associated with the toys advertised - games and competitions especially - were unique to each ad. Consequently, all the shots relative to these initiatives concerned one country alone.

It is evident that altering the video track helps blend the product and the message associated with it into the viewer's context, taking account of the values, traditions and modes of play spe- 
cific to the national child culture. At the same time, the iconic material is adapted in order to position the product with respect to the characteristics of the national market.

\section{Language}

However, the most evident changes concerned the linguistic elements of the message. The voice-overs, dialogues and monologues were translated, adapted, rewritten and dubbed. The superimposed texts were written anew and substituted. These variations performed two functions. First, they gave sense to the commercial without distorting it; second, they connected the message to the context in which it was transmitted. This major effort of 'faithful re-invention' highlights that 'global' advertising campaigns must necessarily take account of specific national features.

Some of the international commercials examined sought to reduce the gap between the foreign elements in the message and the target culture. The aim was to attune the toy and the message to young television viewers mainly by means of language. Dubbing helps conceal the foreign origin of a commercial. The children were unaware that a message which seemed specifically addressed to them, in their language, was in fact a version of one used in an international campaign. Moreover, the commercials analysed never made reference to the provenance of the product: the young television watcher, in fact, did not know where the product had been made, and the meanings associated with the toy were entirely unrelated to its mode and place of manufacture. Images devoid of any territorial reference were often accompanied by a voice-over made easily recognisable as a particular nationality through the use of children's slang. In the French version for the Bratz doll commercial, for example, the voice-over used expressions such as 'trop top', 'super', 'carrément canon' typical of the argot of French children. This solution was obviously the result of an endeavour to

\section{The use of foreign words in advertising messages generally fulfils the function of attracting attention, of differentiating the message, and of assisting its memorisation}

present the product in terms as familiar as possible. The voice-over guided the young viewers, providing not only semantic coherence to the images but also but also fitting the product in the context of their culture.

In other commercials, by contrast, the foreign elements were deliberately emphasised. In this case, too, language played a key role. Some toys kept their English names: 'FurReal \& Friends', 'Hot Wheels Turbo fet City', 'Matchbox Hero City Ice Mountain'. Likewise, some slogans were not translated: for example, the Hasbro brand's 'Make the World Smile' or LEGO's 'Play On'. The use of foreign words in advertising messages generally fulfils the function of attracting attention, of differentiating the message, and of assisting its memorisation (Ray, Ryder \& Scott 1994). Nevertheless, the examples analysed showed that the English language is also used because of its evocative power, in that it connotes fashion, novelty and dynamism. It is no coincidence that children's slang, especially in Germany, is particularly rich with English words. Slogans in a foreign language therefore seem to constitute 'linguistic stereotypes' and assume value independent of their meaning. Advertising tends to desemanticise language, reducing it to pure sound: what matters is the sonority of foreign expressions. In other words, what seems to be important is that the young receiver should be able to identify the foreign language as such, without necessarily being able to comprehend its meaning. 


\section{Conclusions}

The comparative analysis highlighted the presence of a homogeneous set of strategies and contents which transcend French, Italian and German boundaries. Often inextricably bound up with the commercial strategies used to market an audiovisual product and its derivatives, toy advertising taps into highly general stereotypes, common denominators, and widely shared desires. The promotion of the toys manufactured by multinationals thus relies on motifs, symbols and values assumed to be shared by children of different nationalities. It draws on national and local traditions which the promotion makes universal, or it invents immediately universal themes.

However, the transnational advertising of toys cannot escape local obstacles: socio-cultural variables, in fact, are unavoidable constraints. Despite the standardisation of products targeted towards children, their advertising must necessarily be adapted. Commercials for toys produced by large multinationals mimic national socio-cultural realities by altering iconic and verbal elements. By means of minimal adjustments, nuances of translation, changes of apparently insignificant details, the message is fitted to the territory where it is broadcast. In this way, though children of different nationalities seem to have fun with the same toys, they do not play the same game.

\section{References}

Acuff, D. S. and Reiher, R. H. (1997) What kids buy and why. The psychology of marketing to kids. New York: The Free Press.

De Iulio, S. (2001) 'Les spots publicitaires transnationaux: des solutions à géométrie variable', Les Dossiers de l'Audiovisuel, 99, pp.64-66.

De Iulio, S. (2004) 'Publicité transnationale et culture enfantine', pp. 151-162, in N. Diasio (ed.), $A u$ Palais de Dame Tartine. Regards européens sur la consommation enfantine. Paris: L'Harmattan.

de la Ville, I. (2004) 'L'activité de consommation enfantine: les prémices d'un dialogue transdisciplinaire?', pp. 27-41, in N. Diasio (ed.), Au Palais de Dame Tartine. Regards européens sur la consommation enfantine. Paris: L'Harmattan.

de Mooij, M. (1998) Global marketing and advertising: understanding cultural paradoxes. London: Sage.

Klein, N. (2000) No logo. Taking aim at the brand bullies. Toronto: Vintage Canada.

Kline, S. (1993) Out of the Garden : toys, TV and children's culture in the age of TV marketing. New York: Verso.

Kline, S. (1995) 'The play of the market: On the Internationalization of Children's Culture', Theory, Culture and Society. 12, pp.103-129.

Macklin, C. M. (1999) Advertising to Children: Concepts and Controversies, London: Sage.

McNeal, J. U. (1992) Kids as customers. A handbook of marketing to children, New York: Lexington Books.

Ray, N. M., Ryder, M. E. and Scott, V. S. (1994) 'Toward an understanding of the use of foreign words in print advertising', in T. R. Hassan and J. R. Kaynak (eds.), Globalisation of Consumer Markets: Structures and Strategies. New York: Haworth Press.

Roedder-John, D. (1999) 'Consumer socialization of children: a retrospective look at twenty-five years of research', Fournal of Consumer Research, 26, 3, pp. 183-213.

Young, B. M. (1991) Television Advertising and Children. Oxford.

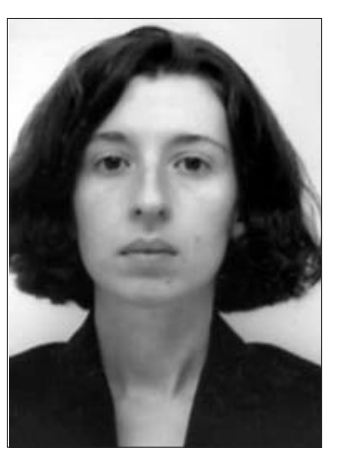

Simona De lulio is Maître de conférences (Associate Professor) in Communication Sciences at the University of Strasbourg and member of the GRESEC (Groupe de recherche sur les enjeux de la communication) of the University of Grenoble. Her current research interests include marketing and child culture.

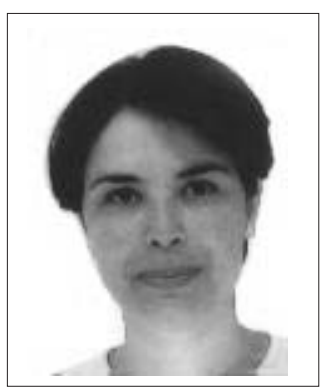

Zouha Dahmen-Jarrin has an MA in Journalism and a PhD. in Communication Sciences. In her work as a researcher at GRESEC, her interests include transnational media and communicational strategies with a focus on on developing countries. 